\title{
Identification and functional characterization of EseH, a new effector of the type III secretion system of Edwardsiella piscicida
}

\author{
Mingyu Hou ${ }^{1}$, Ran Chen ${ }^{1}$, Dahai Yang ${ }^{1,2,3}$, Gabriel Núñez ${ }^{4}$, Zhuang Wang ${ }^{1}$, Qiyao \\ Wang $^{1,2,3}$, Yuanxing Zhang ${ }^{1,2,3}$, Qin Liu ${ }^{1,2,3 *}$
}

${ }^{1}$ State Key Laboratory of Bioreactor Engineering, East China University of Science and Technology, Shanghai 200237, China

${ }^{2}$ Shanghai Engineering Research Center of Marine Cultured Animal Vaccines, Shanghai 200237, China

${ }^{3}$ Shanghai Collaborative Innovation Center for Biomanufacturing, Shanghai 200237, China

${ }^{4}$ Department of Pathology and Comprehensive Cancer Center, University of Michigan, Ann Arbor, MI 48109, USA

* Corresponding author: Qin Liu, qinliu@ecust.edu.cn

This is the author manuscript accepted for publication and has undergone full peer review but has not been through the copyediting, typesetting, pagination and proofreading process, which may lead to differences between this version and the Version of Record. Please cite this article as doi: $10.1111 / \mathrm{cmi} .12638$

This article is protected by copyright. All rights reserved. 


\section{SUMMARY}

Edwardsiella piscicida, a bacterial pathogen in fish and humans, expresses a type III secretion system (T3SS) that is critical for pathogen virulence and disease development. However, little is known about the associated effectors and their functional importance. In this study, we identified the ETAE_1757 encoded protein, termed here E. piscicida secretion effector $\mathrm{H}(\mathrm{EseH})$ as a novel T3SS effector. We found that upon infection with E. piscicida, EseH is translocated into nucleus of host cells which required the T3SS. Homology modeling analysis suggests that EseH is an enzyme that belongs to the family of phosphothreothine lyases. Consistently, EseH inhibited phosphorylation of ERK1/2, p38 $\alpha$ and JNK MAPK pathways in host cells, but had no effect on the NF- $\mathrm{B}$ B pathway. Furthermore, mutation of the critical amino acid residues predicted to confer phosphothreonine lyase activity abolished the ability of EseH to inhibit phosphorylation of ERK1/2, p38 $\alpha$ and JNK MAPK pathways in host cells. In addition, we found an increase in transcript levels of TNF- $\alpha$, IL-12, IL-10 and IFN- $\gamma$ in zebrafish infected with the eseH mutant when compared with the wild type bacterium. Importantly, the virulence of E. piscicida deficient in $E s e H$ was highly attenuated in the zebrafish infection model which correlated with decreased loads of the mutant bacterium in both liver and kidney. Complementation of the $E$. piscicida mutant strain with EseH restored virulence in zebrafish. These results identified EseH as a critical T3SS effector that contributes to virulence by targeting MAPK signaling during E. piscicida infection.

KEY WORDS: Edwardsiella piscicida, T3SS effector, EseH, MAPK pathway 


\section{INTRODUCTION}

Gram-negative bacterial pathogens often use type III secretion systems (T3SS) to inject effector proteins into host cells, to target host signaling pathways, and to promote pathogenicity (Abramovitch et al., 2006; Alfano and Collmer, 2004; Galan and Wolf-Watz, 2006). Although the structural components of T3SS are relatively conserved, the amino acid sequences and functions of individual effectors secreted from T3SS can be highly divergent in different species of pathogenic bacteria (Galán and Collmer, 1999). In addition, pathogenic bacteria deliver a wide repertoire of effector proteins that can suppress host immunity through overlapping or distinct molecular mechanisms (Escoll et al., 2016; Ham et al., 2011; Saijo and Schulza-Lefert, 2008). Recent findings have uncovered novel strategies by which T3SS effector proteins target evolutionarily conserved host MAP kinase (MAPK) signaling cascades and suppress host immune responses (Shan et al., 2007; Bhavsar et al., 2007; Wei et al., 2012).

Early immune responses are activated by sensing of different microbe-associated molecular patterns (MAMPs), such as bacterial flagellin (Akira et al., 2006), lipopolysaccharide (Ausubel, 2005) and peptidoglycan (Dong et al., 2002; He et al., 2006; Nürnberger et al., 2004) during pathogen infection. In plants and animals, stimulation of immune receptors by MAMPs leads to the activation of multiple signaling pathways and their associated transcriptional networks of which the activation of MAPK signaling is a frequent target of T3SS effectors (Akira et al., 2006; Ausubel, 2005; Dong et al., 2002; He et al., 2006; Nürnberger et al., 2004). Several studies have provided evidence that the Shigella T3SS effector OspF directly targets and inhibits the activation of host MAPK signaling cascades resulting in increased pathogen survival and proliferation at the initial infection site (Arbibe et al., 
2007; Kramer et al., 2007; Li et al., 2007). OspF exhibits an unexpected phosphothreonine lyase activity on extracellular signal-regulated protein kinases (ERK) 1/2, p38 kinases and c-Jun NH2-terminal kinases (JNK), dampening the host immune response to the pathogen (Li et al., 2007). Furthermore, Salmonella enterica serovar Typhimurium SPI-2 T3SS dependent effector, SpvC, was shown to have phosphothreonine lyase activity on full-length ERK phosphorylated at Thr202 and Tyr204, which mediate systemic virulence in mice (Mazurkiewicz et al., 2008; Haneda et al., 2012). In addition to SpvC, HopAI1 from Pseudomonas syringae (Li et al., 2007; Jie et al., 2007) possess comparable phosphothreonine lyase activity indicating that pathogens use T3SS effectors to inhibit host MAPK signaling pathways.

Edwardsiella piscicida (Edwardsiella tarda), a facultative intracellular bacterium, belonging to the family Enterobacteriaceae, is one of the most well characterized species in the family (Mohanty and Sahoo, 2007; Shao et al., 2015), which causes gastrointestinal and systemic infections such as myonecrosis, septic arthritis, and wound infections in humans (Schlenker and Surawicz, 2009; Leung et al., 2009). E. piscicida is able to invade and replicate in various cells, including Hep-2 (Stauss et al., 1997, Okuda et al., 2008), HeLa (Osuna et al., 1984), epithelioma papillosum of carp (EPC) (Tan et al., 2005; Wang et al., 2013), macrophage-like cells J774A.1 (Okuda et al., 2006) and fish primary phagocyte (Tan et al., 2005). Recently, E. piscicida was reported to induce caspase-1-dependent cell death in macrophages during infection (Xie et al., 2014). And we also found that E. piscicida replicates and induces a caspase-1-dependent cell pyroptosis in a murine macrophage model, revealed that the macrophage-released population gains enhance infectivity for host epithelial cells and increases resistance to multiple host defenses and hence displays significantly 
promoted virulence in vivo (Zhang et al., 2016). Furthermore, this macrophagereleased population displays a reprogrammed transcriptional profile with significantly up-regulated type III secretion system (T3SS)/T6SS-related genes (Zhang et al., 2016). However, the roles of these potential virulence effectors during the bacterial infection remains unknown.

In this study, we first confirmed the up-regulation transcriptome profile of ETAE_1757 in macrophage-released E. piscicida, then identified this gene encoded protein as a new E. piscicida T3SS effector which was named as EseH (E. piscicida secretion effector $\mathrm{H})$. EseH shares the phosphothreonine lyase activity of the bacterial T3SS effector family. We demonstrate that EseH inhibits the activation of ERK1/2, p38 $\alpha$ and JNK MAPK pathways, but has no effect on the NF- $\kappa B$ pathway. In addition, we found that $E$. piscicida lacking $e s e H$ is highly attenuated in the zebrafish infection model. These findings suggest that the newly identified E. piscicida effector EseH promotes pathogen colonization and virulence by targeting host MAPK signaling pathways.

\section{RESULTS}

\section{Identification of the new $E$. piscicida T3SS effector}

We first assessed the transcription of ETAE_1757 in E. piscicida released from infected murine macrophages cell lines (J774A.1 cells) and DMEM-cultured E. piscicida, and confirmed that ETAE_1757 expression was significantly up-regulated during infection (Fig. 1A, Zhang et al., 2016). To investigate whether the ETAE_1757 encoded protein $(\mathrm{EseH})$ is a secreted T3SS effector, we first constructed an $E$. piscicida strain in which a C-terminus HA-tagged EseH was inserted by homologous recombination on the plasmid puTt, which can replicate within E. piscicida. Then we 
assessed the production of EseH-HA by wild-type and T3SS mutant E. piscicida strains grown in DMEM. Robust induction of EseH-HA was detected in the supernatant of the wild-type E. piscicida, but not in the supernatant of T3SS mutant $E$. piscicida (Fig. 1B). Importantly, comparable production of EseH-HA was observed in the cell pellets of wild-type and T3SS mutant E. piscicida (Fig. 1B). To determine whether EseH was a substrate of E. piscicida T3SS or T6SS, the in-frame fusions of $\beta$-lactamase TEM-1 with eseH were transformed into wild type, T3SS mutant or T6SS mutant E. piscicida, respectively, then the intracellular translocation was assessed by confocal microscopy, as shown in Fig. 1C, the EseH translocation was impaired in T3SS mutant E. piscicida when compared with wild type and T6SS mutant $E$. piscicida, which suggested that EseH was traslocated into cells in a T3SS-dependent manner. Furthermore, the epithelial cell lines (HeLa cells) were infected with wild-type or T3SS E. piscicida carrying a plasmid expressing the EseH-HA fusion protein. After 8 hours of infection, EseH was detected in nucleus of the cells infected with wild-type E. piscicida, but not with the T3SS mutant by immunofluorescence microscopy (Fig. S1). Collectively, these results suggest that EseH can function as a T3SS effector in E. piscicida.

\section{EseH is targeted into the nucleus}

Since E. piscicida EseH can be translocated into host cells via a T3SS-dependent mechanism, we investigated the localization of EseH in host cells. After transient expressing of EseH-HA in $293 \mathrm{~T}$ cells, we observed that EseH was targeted into the nucleus of host cells, compared with EseG that located into cell cytosol, as revealed by immuno-fluorescence microscopy (Fig. 2A and B, Fang et al. 2016), while the cells morphology was not much changed in EseH-transfected cells, compared with control-transfected cells (Fig. S2). Moreover, subcellular fractionation showed that 
EseH localized to the nucleus of transfected-293T cells, but not in the cytosolic or membrane fractions (Fig. 2C). Taken together, the results suggest that E. piscicida EseH can be translocated into host cells in a T3SS dependent manner, and targeted into the nucleus of host cells.

\section{Homology modeling of $E$. piscicida EseH}

We performed sequence based homology searches, motif analysis, and PHYRE2 fold recognition that revealed that EseH contains phosphothreonine lyase activity sites with the critical amino acid sides that are conserved in orthologues in Shigella (OspF), Salmonella (SpvC) and Pseudomonas syringae (HopAI1) (Fig. 3A). These results suggest that EseH is a member of the bacterial T3SS effector family with phosphothreonine lyase activity (Alfano and Collmer, 2004; Mazurkiewicz et al., 2008; Haneda et al., 2012; Brennan et al., 2008). Furthermore, structure modeling revealed that EseH may share the same conserved domain with the T3SS effectors OspF, SpvC and HopAI1 (Fig. 3B). Taking together, these results suggest that $E$. piscicida EseH is a T3SS effector that belongs to the family of phosphothreonine lyases.

\section{EseH inhibits MAPK signaling pathways}

Previous studies showed that phosphothreonine lyases regulate the dephosphorylation of components of the MAPK and NF- $\mathrm{KB}$ signaling pathways (Kramer et al., 2007; Mazurkiewicz et al., 2008; Haneda et al., 2012; Brennan et al., 2008). For example, upon over expression, or in vitro, SpvC can target ERK1/2, p38 $\alpha$ and JNK, but in vivo, under physiological conditions, only ERK1/2 are dephosphorylated (Haneda et al., 2012; Brennan et al., 2008, Mazurkiewicz et al., 2008). Thus, we examined the effects of EseH on the regulation of the MAPK and NF- $\kappa B$ pathways. After infection of HeLa cells with wild-type or $\Delta e s e H$ E. piscicida, we found that activation of 
ERK1/2, p38 $\alpha$ and JNK was enhanced in $\Delta e s e H$ E. piscicida infected cells compared to cells infected with the wild-type strain (Fig. 4). Importantly, the increased activation of MAPK kinases induced by $\triangle e s e H$ E. piscicida was reduced to normal levels in HeLa cells infected with a complemented eseH strain (Fig. 4). Notably, IкB $\alpha$ degradation was not affected by the absence of EseH (Fig. 4). To further clarifying whether the EseH inhibiting the MAPK signaling directly, or act on MAP2K, we examined the effects of EseH on regulation of the MAP2K pathways, and found that activation of MEK1/2, MKK3/6, MKK4 and MKK7 were not affected by the absence of EseH (Fig 4). Collectively, these results indicate that EseH specifically regulates MAPK signaling in infected cells.

\section{Phosphothreonine lyases activity of EseH}

To confirm that EseH regulates MAPK signaling pathways through its putative phosphothreonine lyase activity, we generated EseH mutants in which the conserved lysine and histidine catalytic residues required for phosphothreonine lyase activity were mutated (Mazurkiewicz et al., 2008). We transfected 293T cells with plasmids producing wild-type and mutant $\left(\mathrm{K}^{79} \rightarrow \mathrm{R}^{79}(\mathrm{~K} 79 \mathrm{R}), \mathrm{H}^{81} \rightarrow \mathrm{R}^{81}(\mathrm{H} 81 \mathrm{R})\right.$ and $\mathrm{K}^{111} \rightarrow \mathrm{A}^{111}$ (K111A) EseH and the transfected cells were stimulated with TNF- $\alpha$. Stimulation of $293 \mathrm{~T}$ cells with TNF- $\alpha$ induced activating phosphorylation of ERK1/2, p38 $\alpha$ and JNK MAPK pathways in untransfected 293T cells, but not in cells expressing wild-type EseH (Fig. 5). Importantly, activation of MAPKs induced by TNF- $\alpha$ was unimpaired in 293 T cells expressing the EseH mutants (Fig. 5). The results suggest that the $E$. piscicida T3SS effector, EseH, regulates MAPK signaling cascades through its phosphothreonine lyase activity.

\section{Role of EseH in $E$. piscicida infected zebrafish}

The MAPK signaling cascades regulates the transcriptional activation of a wide array 
of pro-inflammatory genes (Akira et al., 2006; Dong et al., 2002). To assess the immunomodulatory activity of EseH, we assessed the expression of cytokines in zebrafish infected with wild-type and mutant E. piscicida. Infection with wild-type E. piscicida induced the expression of TNF- $\alpha$, IL-12, IL-10 and IFN- $\gamma$ transcripts, which was further enhanced in zebrafish infected with the eseH mutant (Fig. 6A). The enhancement of cytokine expression observed with eseH mutant was abolished when zebrafish were infected with the complemented eseH E. piscicida strain (Fig. 6A). To further assess whether EseH regulates the virulence of E. piscicida in vivo, we infected adult zebrafish with wild-type and eseH mutant and monitored fish survival after infection. Zebrafish infected with wild-type E. piscicida or complemented eseH strain showed marked mortality with $\sim 80 \%$ of the animals succumbing by day 3-4 post-infection whereas only $\sim 30 \%$ of fish succumbed to infection with the eseH mutant (Fig. 6B). To assess whether EseH regulates pathogen colonization in fish tissues, we determined the bacteria burden in the liver and kidney of fish infected intramuscularly with 100 wild- type, eseH mutant or complemented eseH E. piscicida strain. We found that colonization of the eseH mutant strain was comparable to the wild-type strain at $48 \mathrm{hrs}$ in the liver and kidney, but was undetectable by $72 \mathrm{hrs}$ post infection (Fig. 6C). In contrast, there was clear colonization of the wild-type and complemented eseH E. piscicida strains in the liver and kidney $72 \mathrm{hrs}$ after infection (Fig. 6C). These results indicate that EseH is important for the virulence and colonization of E. piscicida in zebrafish.

\section{DISCUSSION}

The bacterial T3SS virulence factors are injected into eukaryotic cells and inhibit signaling by irreversibly inactivating MAPKs (Shan et al., 2007; Bhavsar et al., 2007; 
Wei et al., 2012). Previous study revealed that the Salmonella T3SS virulence factor, SpvC, is required for bacteria virulence in mice infection model (Gulig et al., 1990; Matsui et al., 2001; Haneda et al., 2012). Shigella OspF, which shares 71\% sequence identity with SpvC, attenuates the recruitment of polymorphonuclear leukocytes in mouse lung infection model (Arbibe et al., 2007). E. piscicida is an intracellular pathogen that uses T3SS to promote its lifestyle in both epithelial and phagocytic cells, which contributes to virulence upon contact with target cells (Tan et al., 2005; Okuda et al., 2006; Srinivasa et al., 2004; Xie et al., 2010; Xie et al., 2015). Previous works indicated that deletion of a single gene, such as eseB, eseD, escA, eseC or esaN, reduces virulence in blue gourami fish (Wang et al., 2009; Zheng et al., 2007). Mutation any of the Ese genes impairs T3SS function with the exception of EseG, the first characterized effector in E. piscicida, which has been shown to disassemble microtubule structures when overexpressed in mammalian cells, while deletion of ese $G$ gene results in attenuated virulence in the blue gourami fish infection model (Xie et al., 2010). Another identified E. piscicida effector, EseJ, contributes to virulence by reducing bacterial adhesion to EPC cells and contributes to the $E$. piscicida pathogenesis by infection with blue gourami fish in vivo (Xie et al., 2015). Apart from these two effectors, little is known about the T3SS effectors of this important fish pathogen. Our results indicate that the newly identified T3SS effector, EseH, does contribute to virulence of E. piscicida in zebrafish infection model, which will shed light on better understanding of the complex role of bacterial T3SS effectors in regulation of host immune responses, and their contribution to systemic infection.

Localization of phosphothreonine lyases is an important factor for specificity because some physiological targets of MAPKs exist only in certain cellular compartments. There seem to be differences between phosphothreonine lyases even though the 
bacteria replicate in epithelial cells and macrophages. Salmonella SpvC is translocated into the cytoplasm of infected macrophages and cervical epithelial (HeLa) cells, where it is susceptible to degradation (Mazurkiewicz et al., 2008); However, in HeLa cells, Shigella OspF co-localizes with microtubules and accumulates in the nucleus despite lacking a nuclear-localization signal (Zurawski et al., 2006), this leads to the dephosphorylation of nuclear ERK (Arbibe et al. 2007). However, the localization of other phosphothreonine lyases remains unknown. In this study, our results provided the evidence that E. piscicida phosphothreonine lyase, EseH, was translocated into the nucleus of infected epithelial cells, and leads to the dephosphorylation of ERK, p38 and JNK signaling.

Phosphothreonine lyases are specific for pThr-Xaa-pTyr motifs present in MAPKs (Li et al., 2007), however, the identity of the physiological substrates of these enzymes still need further clarification. In contrast to the activity of OspF- or SpvC-deficient mutants, wild type Shigella and Salmonella infections reduce JNK, p38 and ERK phosphorylation (Li et al., 2007). However, Arbibe et al. did not observe reduced JNK phosphorylation in Shigella infected Caco-2 cells (Arbibe et al., 2007). Furthermore, transient OspF expression in the SW480 colorectal cancer cell line reduces ERK phosphorylation (Kim et al., 2008). Haneda et al. also suggested that SpvC only dephosphorylate ERK1/2 in vivo (Haneda et al., 2012). Phosphothreonine-lyasedependent dephosphorylation of recombinant p38, ERK and JNK is detected in vitro, although JNK is not dephosphorylated by Shigella under bacterial infection (Mazurkiewicz et al., 2008; Arbibe et al., 2007; Li et al., 2007). However, during Shigella flexneri infection, OspF was proved to potentiate the activation of the JNK and NF- $\mathrm{KB}$, within the phosphothereonine lyase activity on $\mathrm{p} 38$, and results from the disruption of a negative feedback loop regulation between p38 and TGF-beta 
activated kinase 1 (Veronika et al. 2011). In this study, our results provide evidence that EseH from the pathogen E. piscicida as a new T3SS effector with phosphothreonine lyase activity, that specifically inhibits phosphorylation of ERK1/2, p38 $\alpha$ and JNK, both under bacterial infection and transient expression in host cells. However, further comparative mass spectrometry analysis is required to analyze the post-translational modifications that lead to unsaturated amino acids catalyzed by phosphothreonine lyases. 


\section{EXPERIMENTAL PROCEDURES}

\section{Bacterial strains and culture conditions}

The bacterial strains used in this study are listed in Table S1. The E. piscicida wild-type strain used in this study was EIB202. E. coli DH5 $\alpha, \operatorname{cc} 118 \lambda$ pir and SM10 $\lambda$ pir were used as hosts for the construction of plasmids and for the conjugation of the pir-dependent suicide plasmid. E. coli were grown in Luria-Bertani (LB) broth or on LB agar at $37{ }^{\circ} \mathrm{C}$, while E. piscicida strains were grown in Trypticase Soy Broth (TSB), Dulbecco's modified essential medium (DMEM), or on tryptic soy agar (TSA) at $30^{\circ} \mathrm{C}$. Antibiotics were added to the media at the following concentrations: ampicillin (Amp), $100 \mu \mathrm{g} / \mathrm{ml}$; kanamycin $(\mathrm{Km}), 50 \mu \mathrm{g} / \mathrm{ml}$; colistin $(\mathrm{Col}), 16.7 \mu \mathrm{g} / \mathrm{ml}$; tetracycline (Tet), $12.5 \mu \mathrm{g} / \mathrm{ml}$.

\section{Construction of plasmids and mutant strains}

To construct the E. piscicida eseH deletion strain, an in-frame deletion mutation of eseH was generated by sacB-based allelic exchange. Two PCR fragments were generated from EIB202 genomic DNA for the construction of the $\Delta e s e H$ mutant by overlapping PCR. The fragement upstream were constructed using primer pairs deletion-eseH-P1 and -P2, and the fragment downstream were constructed using primers deletion-eseH-P3 and -P4. The PCR products containing a deletion from amino acid (aa) 9 to aa 211 of EseH, then cloned into the $s a c B$ suicide vector pDMK, linearized with BglII and SphI, and the resulting plasmids were used to transform $E$.

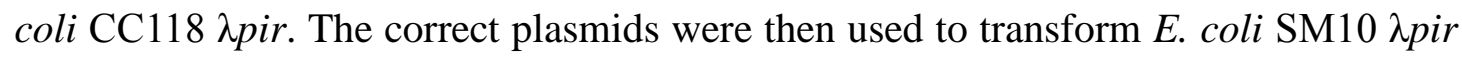
and then conjugated into EIB202. Transconjugants with the plasmids integrated into the chromosome by homologous recombination were selected on tryptic soy agar (TSA) medium containing kanamycin or colistin. To complete the allelic exchange for in-frame deletions, double-crossover events were counter-selected on TSA plates 
containing 10\% sucrose. All the mutants were confirmed by PCR amplification of the respective DNA loci, and subsequent DNA sequencing of each PCR product. The primers used in this study are listed in Table S2. We constructed puTt-pro0456-eseH-HA using one step cloning kit (Vazyme) to express constitutively EseH in E. piscicida. The plasmid was electroporated into the $\Delta e s e H$ strain to complement the mutant strain, and into wild-type and $\Delta \mathrm{T} 3 \mathrm{SS}$ strains to generate strains over expressing EseH.

The DNA sequence of eseH gene was amplified with primers pCX340-eseH-F and pCX340-eseH-R (listed in Table S2) and ligated into the NdeI and KpnI restriction sites of pCX340 to create pCX340-eseH. And DNA sequence of eseG gene was amplified with primers pCX340-eseG-F and pCX340-eseG-R (listed in Table S2) and ligated into the EcoR and KpnI restriction sites of pCX340 to create pCX340-eseG.

To construct plasmids expressing eseH-HA, eseH (K79R)-HA, eseH (H81R)-HA and eseH (K111A)-HA in eukaryotic cells, plasmid pCDH was linearized with XbaI and BamHI and the PCR products of eseH-HA, eseH (K79R)-HA, eseH (H81R)-HA and eseH (K111A)-HA containing compatible ends were inserted into the linearized pCDH plasmid using one step cloning kit.

\section{Cell cultures, infection and transfection}

J774A.1, HeLa and 293T cells were cultured in Dulbecco's modified essential medium (DMEM, Sigma) supplemented with 10\% fetal bovine serum (FBS). J774A.1 was infected at a multiplicity of infection (MOI) of 10:1, in DMEM containing 10\% (vol/vol) FBS (growth medium, GM) and gentamicin $(100 \mu \mathrm{g} / \mathrm{ml}$ ) was added 2 hours after infection for 30 min to kill extracellular bacteria, followed by GM containing 10 $\mu \mathrm{g} / \mathrm{ml}$ gentamicin for the remainder of the experiment. HeLa cells were infected at a 
MOI of 100. Before infection, the culture medium was changed to serum-free medium (SFM) for 12-16 hours. 293T cells were transfected using standard calcium phosphate method, and the medium changed to SFM for 12-16 hours before TNF- $\alpha$ stimulation.

\section{RNA extraction and quantitative real-time PCR}

J774A.1 cells were infected as described above, and the extracellular bacteria were harvested at 8 hours post infection. E. piscicida were also cultured in medium and harvested as DMEM-cultured samples. RNA of both samples was extracted using an RNA isolation kit (Tiangen, Beijing, China). One microgram of each RNA sample was used for cDNA synthesis with the MMLV reverse transcriptase (ToYoBo, Tsuruga, Japan). RT-PCR was carried out on a FTC-200 detector (Funglyn Biotech, Shanghai, China) using the SYBR green real-time PCR kit (ToYoBo). Total RNA from whole fish was prepared as described above. The expression of TNF- $\alpha$, IL-12, IL-10 and IFN- $\gamma$ was determined using real-time PCR (ABI Step One qPCR). Each primer pair (Table S2) was designed using NCBI/Primer-BLAST. The expression of each gene was normalized to that of the $\beta$-actin transcript and expressed as -fold change relative to the expression seen in PBS-injected zebrafish. All quantitative PCRs were performed for three biological replicates, and the data for each sample were expressed relative to the expression level of the $\beta$-actin gene by using the $2^{-\Delta \Delta \mathrm{CT}}$ method.

\section{Secretion assay}

For analysis of protein secretion under T3SS inducing conditions, E. piscicida strains were grown overnight in TSB medium and then subcultured 1:100 in fresh DMEM and grow for an additional 12 hours. L-arabinose was added to induce the expression of EseH-HA when $\mathrm{OD}_{600}$ was 0.6. To ensure that protein from equal numbers of cells was analyzed, protein samples were adjusted to a volume in which $1 \mathrm{ml}$ of culture corresponds to $\mathrm{OD}_{600}=1$. Bacteria were collected in $50 \mathrm{ml}$ tubes, and centrifuged at 
$5,000 \mathrm{~g}$ for $10 \mathrm{~min}$ at $4{ }^{\circ} \mathrm{C}$. Extracellular proteins were obtained by ultrafiltration from supernatants, which were filtered through a $0.22 \mu \mathrm{m}$ filter membrane unit (Millipore, Darmstadt, Germany) with a $10 \mathrm{kD}$ molecular weight cut-off Amicon Ultra-15 centrifugal filter device (Millipore). 150 micrograms of each protein was boiled for 15 min in SDS sample buffer, and stored at $-20{ }^{\circ} \mathrm{C}$ before western blot analysis.

\section{TEM1 protein translocation assay}

The translocation of translational fusions between TEM1 and EseH was evaluated by detecting $\beta$-lactamase activity in infected HeLa cells as previously described (Sory et al., 1995). Briefly, TEM1 fusions (pCX340-eseH, described in Tabel S1) were transformed into wild type and T3SS E. pisicida by electroporation. Bacteria were grown in TSB overnight at $30^{\circ} \mathrm{C}$, then diluted into DMEM and grown standing at $30^{\circ} \mathrm{C}$ until $\mathrm{OD}_{600}$ reached to 0.8 . HeLa cells were then infected with strains harbouring the TEM1 fusions at a MOI of 100. Infected cells were centrifuged at 400 $g$ for 10 min to initiate bacterial-cell contact followed by incubation at $35^{\circ} \mathrm{C}$ for $3 \mathrm{~h}$ after which the cells were washed 3 times and incubated with fresh DMEM without serum for another $4 \mathrm{~h}$. At this time point, cells were washed three times with DMEM and loaded with the fluorescent substrate CCF2/AM (LiveBLAzer-FRET B/G loading kit; Invitrogen) in the $\beta$-lactamase loading solution supplemented with $15 \mathrm{mM}$ Probenecid (Invitrogen). Cells were incubated in dark for $120 \mathrm{~min}$ at room temperature and then observed under a Nikon A1R confocal microscope. At least 400 cells were counted in triplicate wells to determine the percentage of cells emitting a blue fluorescence (TEM1-positive).

\section{Fractionation assay of transfected HEK293T cells}

$293 \mathrm{~T}$ cells were seeded at $6 \times 10^{5}$ cells per well into 6-well plates. After transfection, 
cells were lysed in $\mathrm{HB}$ buffer $(250 \mathrm{mM}$ sucrose, $150 \mathrm{mM} \mathrm{NaCl}, 3 \mathrm{mM}$ imidazole, and $0.5 \mathrm{mM}$ EDTA with $\mathrm{pH} 7.4$ ), then centrifuged at $3,000 \mathrm{~g}$ for $15 \mathrm{~min}$ at $4{ }^{\circ} \mathrm{C}$. The precipitate was component of cell membrane, which was then resuspended with 240 $\mu \mathrm{l}$ HB buffer mixed with protein loading buffer, boiled, and centrifuged. The supernatant was used to fractionate component of cytosol and nucleus using nuclear and cytoplasmic protein extraction kit (Beyotime Institute of Biotechnology, Jiangsu, China) according to the manufacturer's instructions.

\section{Fluorescence microscopy}

HeLa cells or $293 \mathrm{~T}$ cells were seeded at $1.5 \times 10^{5}$ cells per well into 24 -well plates with coverslips at the bottom of the wells. After infection of HeLa cells, or transfection of 293 T cells, the cells were washed with PBS three times and then fixed with 4\% (wt/vol) paraformaldehyde for $10 \mathrm{~min}$ at room temperature. Fixed cells were washed in PBS and permeabilized with $0.1 \%$ Triton $\mathrm{X}-100$ for $10 \mathrm{~min}$ at room temperature. After washing with PBS, EseH-HA was stained with anti-HA for $30 \mathrm{~min}$ and nuclei were stained with DAPI (Sigma) for $10 \mathrm{~min}$ at room temperature, respectively. Fixed samples were viewed on a Nikon A1R confocal microscope. Images were analyzed using ImageJ (NIH).

\section{Western blot and antibodies}

Cells were lysed in $50 \mathrm{mM}$ Tris, $150 \mathrm{mM} \mathrm{NaCl}, 1 \%$ Triton X-100, and $1 \mathrm{mM}$ EDTA with $\mathrm{pH}$ 7.4. Lysates were mixed with protein loading buffer, boiled, and centrifuged. $10 \mu \mathrm{l}$ of the cell lysate was separated by SDS-PAGE on a $12 \%$ gel and transferred to PVDF membrane (Millipore), then probed with specific antibodies, and antibody binding detected by chemiluminescence. The signal intensities were quantitatively analyzed by NIH ImageJ. 
Antibodies for HA and $\beta$-actin were purchased from Hua'an Bio. Antibody for RNAP was purchased from Santa Cruz. Antibodies for IкB $\alpha$, ERK1/2, phospho-ERK1/2, p38 $\alpha$, phospho-p38 $\alpha$, JNK and phospho-JNK were purchased from Cell Signaling Technology. Antibodies for phospho-MEK1/MEK2 and phospho-MKK4 were purchased from R\&D systems, and antibodies for phospho-MKK3/MKK6 and phospho-MKK7 were purchased from Cell Signaling Technology. HRP-conjugated anti-mouse or anti-rabbit antibodies were purchased from Beyotime.

\section{Infection of $E$. piscicida in zebrafish}

Zebrafish (Danio rerio) weighing $0.3 \pm 0.1 \mathrm{~g}$ were obtained from the animal center at East China University of Science and Technology (Shanghai, China). The fish were stocked in $10 \mathrm{~L}$ tanks and maintained at $22 \pm 2{ }^{\circ} \mathrm{C}$ in a zebrafish cultivation system with a photo-period of 12:12 h (light:dark) and recirculating fresh water within the fresh water aquarium pathogen containment facility. The fish were fed ad libitum daily with commercial pellets (Bloodworms, Rainone, Beijing) and acclimated to the tanks for at least 1 week prior to commencing the experiments. All of the zebrafish were handled in compliance with the local animal welfare regulations and maintained according to standard protocols (http://ZFIN.org).

Healthy zebrafish were infected with E. piscicida strains as described previously by Yang et al. (34) with slight modifications. E. piscicida were grown in Trypticase Soy Broth (TSB) at $30^{\circ} \mathrm{C}$ before infection. Dose of 100 bacteria were injected intramuscularly near the dorsal fins, with 30 fish per infection. Fish mortalities were recorded over a period of 7 days. At indicated time points, the infected fish were anesthetized, and the livers and kidneys were sampled from 5 fish and pooled for bacteria count. 


\section{Statistical analysis}

Statistical analysis was performed using GraphPad Prism program (GraphPad Software). All data were representative of at least three independent experiments and were presented as mean \pm SD (standard deviation). Differences between two groups were evaluated using Student's t test. One-way ANOVA test was used to analyze differences among multiple groups. Differences in fish survival were assessed using the Long-rank (Mantel-Cox) test. Statistical significance was defined as $* p<0.05$. 


\section{AUTHORS CONTRIBUTIONS}

Q.L., D.Y. and M.H. conceived the study; M.H. performed the majority of experiments, R.C. and Z.W. did the zebrafish infection experiments; M.H., D.Y., Q.W., Y.Z., G.N. and Q.L. analyzed the data and wrote the manuscript. All authors discussed the results and commented on the manuscript.

\section{ACKNOWLEDGEMENTS}

We thank Dr. Melody Y. Zeng and Dr. Yuan He from the University of Michigan Medical School for critical review of the manuscript. This work was supported by the National Natural Science Foundation of China (31430090 and 31472308) and the

Chinese National High Technology Research and Development Program (2013AA093101).

\section{CONFLICTS INTERESTS}

The authors declare there are no conflicts interests. 


\section{REFERENCES}

Abramovitch RB, Anderson JC, Martin GB. (2006) Bacterial elicitation and evasion of plant innate immunity. Nat Rev Mol Cell Biol 7: 601-611.

Akira S, Uematsu S, Takeuchi O. (2006) Pathogen recognition and innate immunity. Cell 124: 783-801.

Alfano JR, Collmer A. (2004) Type III secretion system effector proteins: Double agents in bacterial disease and plant defense. Annu Rev Phytopathol 42: 385-414.

Arbibe L, Kim DW, Batsche E, Pedron T, Mateescu B, Muchardt C, Parsot C, Sansonetti PJ. (2007) An injected bacterial effector targets chromatin access for transcription factor NF-kappaB to alter transcription of host genes involved in immune responses. Nat Immunol 8: 47-56.

Ausubel FM. (2005) Are innate immune signaling pathways in plants and animals conserved? Nat Immunol. 6: 973-979.

Bhavsar AP, Guttman JA, Fimlay BB. (2007) Manipulation of host-cell pathways by bacterial pathogens. Nature 449: 827-834.

Brennan D, Roe S M, Barford D. (2008) Structure and mechanism of the Chromobacterium violaceum VirA phosphothreonine lyase. FEBS J 275: 268-268.

Charpentier X and Oswald E. (2004) Identification of the secretion and translocation domain of the enteropathogenic and enterohemorrhagic Escherichia coli effector Cif, using TEM-1 $\beta$-lactamase as a new fluorescence-based reporter. J Bacteriol 186: 5486-5495.

Chisholm ST, Coaker G, Day B, Staskawicz BJ. (2006) Host-microbe interactions: Shaping the evolution of the plant immune response. Cell 124: 803-814.

Dong C, Davis RJ, Flavell RA. (2002) MAP kinases in the immune response. Annu Rev Immunol 20: $55-72$.

Escoll P, Mondino S, Rolando M, Buchrieser C. (2016) Targeting of host organelles by pathogenic bacteria: a sophisticated subversion strategy. Nat Rev Microbiol 14: 5-19. 
Fang S, Zhang L, Lou Y, Yang D, Wang Q, Zhang Y, Liu Q. (2016) Intracellular Translocation and Localization of Edwardsiella tarda Type III Secretion System Effector EseG in Host Cells Microbial Pathogenesis doi: 10.1016/j.micpath.2016.05.008.

Galán JE, Collmer A. (1999) Type III secretion machines: bacterial devices for protein delivery into host cells. Science 284: 1322-1328.

Galan JE, Wolf-Watz H. (2006) Protein delivery into eukaryotic cells by type III secretion machines. Nature 444: 567-573.

Gulig, PA and Chiodo, VA. (1990) Genetic and DNA sequence analysis of the Salmonella typhimurium virulence plasmid gene encoding the 28,000-molecular-weight protein. Infect. Immun. 58, 2651-2658

Ham H, Sreelatha A, Orth K. (2011) Manipulation of host membranes by bacterial effectors. Nat Rev Microbiol 9:635-646.

Haneda T, Ishii Y, Shimizu H, Ohshima K, Lida N, Danbara H, Okada N. (2012) Salmonella type III effector SpvC, a phosphothreonine lyase, contributes to reduction in inflammatory response during intestinal phase of infection. Cell Microbiol 14: 485-499.

He P, Shan L, Lin NC, Martin GB, Kemmerling B, Nurnberger T, Sheen J. (2006) Specific bacterial suppressors of MAMP signaling upstream of MAPKKK in Arabidopsis innate immunity. Cell 125: 563-575.

Jie Z, Feng S, Yan L, Haitao C, Linjie C, Hongtao L, Yan Z, Chengzu L, Lefu L, Jijie C, She C, Xiaoyan T, Jian-Min Z. (2007) A Pseudomonas syringae effector inactivates MAPKs to suppress PAMP-induced immunity in plants. Cell Host Microbe 3: 175-185.

Kim, D.W. et al. (2008) OspF directly attenuates the activity of extracellular signal-regulated kinase during invasion by Shigella flexneri in human dendritic cells. Mol. Immunol. 45, $3295-3301$ 
Kramer RW, Slagowski NL, Eze NA, Giddings KS, Morrison MF, Siggers KA, Starnbach MN, Lesser CF. (2007) Yeast functional genomic screens lead to identification of a role for a bacterial effector in innate immunity regulation. PLoS Pathog 3, e21.

Leung KY, Siame BA, Tenkink BJ, Noort RJ, Mok YK. (2012) Edwardsiella tarda-virulence mechanisms of an emerging gastroenteritis pathogen. Microbes Infect 14:26-34.

Li H, Xu H, Zhou Y, Zhang J, Long C, Li S, Chen S, Zhou JM, Shao F. (2007) The phosphothreonine lyase activity of a bacterial type III effector family. Science 315: 1000-1003.

Matsui, H. et al. (2001) Virulence plasmid-borne spvB and spvC genes can replace the 90-kilobase plasmid in conferring virulence to Salmonella enterica serovar Typhimurium in subcutaneously inoculated mice. J. Bacteriol. 183, 4652-4658

Mazurkiewicz P, Thomas J, Thompson JA, Liu M, Arbibe L, Sansonetti P, Holden DW. (2008) SpvC is a Salmonella effector with phosphothreonine lyase activity on host mitogen-activated protein konases. Mol Microbiol 67: 1371-1383.

Meylan E, Tschopp J, Karin M. (2006) Intracellular pattern recognition receptors in the host response. Nature 442: 39-44.

Mohanty BR, Sahoo PK. (2007) Edwardsiellosis in fish: a brief review. J Bioscience 32: $1331-1344$

Nürnberger T, Brunner F, Kemmerling B, Piater L. (2004) Innate immunity in plants and animals: Striking similarities and obvious differences. Immunol Rev 198: 249-266.17.

Okuda J, Arikawa Y, Takeuchi Y, Mahmoud MM, Suzaki E, Kataoka K, Suzuki T, Okinaka Y, Nakai T. (2006) Intracellular replication of Edwardsiella tarda in murine macrophage is dependent on the type III secretion system and induces an up-regulation of anti-apoptotic NF-kappaB target genes protecting the macrophage from staurosporine-induced apoptosis. Microb Pathog 41: 226-240.

Okuda J, Kiriyama M, Yamanoi E, and Nakai T. (2008) The type III secretion system-dependent repression of NF-kappaB activation to the intracellular growth of Edwardsiella tarda in 
human epithelial cells. Fems Microbiol Lett 283:9-14.

Osuna A, Ortega G, Gamarro F, Castanys S, Mascaro MC. (1984) Some factors affecting the in vitro invasion of HeLa cells by Trypanosoma cruzi. Int J Parasitol 14: 253-257

Saijo Y, Schulza-Lefert P. (2008) Manipulation of the eukaryotic transcriptional machinery by bacterial pathogens. Cell Host Microbe 2: 96-99.

Schlenker C, Surawicz CM. (2009) Emerging infections of the gastrointestinal tract. Best Pract Res Clin Gastroenterol 23:89-99.

Shan L, He P, Sheen J. (2007) Intercepting host MAPK signaling cascades by bacterial type III effectors. Cell Host Microbe 1: 167-174.

Shao S, Lai Q, Liu Q, Wu H, Xiao J, Shao Z, Wang Q, Zhang Y. (2015) Phylogenomics characterization of a highly virulent Edwardsiella strain ET080813T encoding two distinct T3SS and three T6SS gene clusters: propose a novel species as Edwardsiella anguillarum sp. nov. Syst Appl Microbiol 38: 36-47.

Sory MP, Boland A, Lambermont I, Cornelis GR. (1995) Identification of the YopE and YopH domains required for secretion and internalization into the cytosol of macrophages, using the cyaA gene fusion approach, Proc Natl Acad Sci USA 92 (26): 11998-2002.

Srinivasa Rao PS, Yamada Y, Tan YP, Leung KY. (2004) Use of proteomics to identify novel virulence determinants that are required for Edwardsiella tarda pathogenesis. Mol Microbiol 53:573-586.

Strauss EJ, Ghori N, and Falkow S. (1997) An Edwardsiella tarda strain containing a mutation in a gene with homology to $\operatorname{shlB}$ and $h p m B$ is defective for entry into epithelial cells in culture. Infect Immun 65:3924-3932.

Tan YP, Zheng J, Tung SL, Rosenshine I, Leung KY. (2005) Role of type III secretion in Edwardsiella tarda virulence. Microbiology 151:2301-2313. 
Wang B, Mo ZL, Mao ZX, Zou YX, Xiao P, Li J, Yang JY, Ye XH, Leung KY, Zhang PJ. (2009) Investigation of EscA as a chaperone for the Edwardsiella tarda type III secretion system putative translocon component EseC. Microbiology 155:1260-1271.

Wang B, Yu T, Dong X, Zhang Z, Song L, Xu Y, Zhang XH. (2013) Edwardsiella tarda invasion of fish cell lines and the activation of divergent cell death pathways. Vet Microbiol $163: 282-289$

Wei P, Wong WW, Park JS, Corcoran EE, Peisajovich SG, Onuffer JJ, Weiss A, Lim WA. (2012) Bacterial virulence proteins as tools to rewire kinase pathways in yeast and immune cells. Nature 488: 384-388.

Xiao Y, Liu Q, Chen H, Zhang YX. (2011) A stable plasmid system for heterologous antigen expression in attenuated Vibrio anguillarum. Vaccine 40: 6986-6993.

Xie HX, Lu JF, Zhou Y, Yi J, Yu XJ, Leung KY, Nie P. (2015) Identification and functional characterization of the novel Edwardsiella tarda effector EseJ. Infect Immun 83:1650-1660.

Xie HX, Yu HB, Zheng J, Nie P, Foster LJ, Mok YK, Brett Finlay B, Leung KY. (2010) EseG, an effector of the type III secretion system of Edwardsiella tarda, triggers microtubule destabilization. Infect Immun 78: 5011-5021.

Yang DH, Liu Q, Yang MJ, Wu HZ, Wang QY, Xiao JF, Zhang YX. (2012) RNA-seq liver transcriptome analysis reveals an activated MHC-I pathway and an inhibited MHC-II pathway at the early stage of vaccine immunization in zebrafish. BMC Genomics 13: 319-334

Zhang LZ, Ni CS, Xu WT, Dai TC, Yang DH, Wang QY, Zhang YX, Liu Q. (2016) Intra-macrophage infection reinforces the virulence of Edwardsiella tarda. J Bacteriol 198: $1534-1542$.

Zhang J, Shao F, Li Y, Cui H, Chen L, Li H, Zou Y, Long C, Lan L, Chai J, Chen S, Tang X, Zhou JM. (2007) A Pseudomonas syringae effector inactivates MAPKs to suppress PAMP-induced immunity in plants. Cell Host Microbe 1, 175-185. 
Zheng J, Li N, Tan YP, Sivaraman J, Mok YK, Mo ZL, Leung KY. (2007) EscC is a chaperone for the Edwardsiella tarda type III secretion system putative translocon components EseB and EseD. Microbiology 153:1953-1962.

Zhu Y, Li H, Long C, Hu L, Xu H, Liu L, Chen S, Wang DC, Shao F. (2007) Structural insights into the enzymaticmechanism of the pathogenic MAPK phosphothreonine lyase. Mol. Cell 28, 899-913.

Zurawski DV, Mitsuhata C, Mumy KL, McCormick BA, Maurelli AT. (2006) OspF and OspC1 are Shigella flexneri type III secretion system effectors that are required for postinvasion aspects of virulence. Infect. Immun. 74, 5964-5976. 


\section{FIGURE LEGENDS}

Figure 1. Identification of EseH, a new $\boldsymbol{E}$. piscicida T3SS effector. (A) Transcript profile analysis of ETAE_1757 by real-time PCR in macrophage-released E. piscicida or DMEM-cultured E. piscicida. Transcript expression of 16S RNA was used as internal control. Data are representative of at least 3 experiments. Graphs show mean $\pm \mathrm{SD}$ of triplicate cultures, $* p<0.05$. (B) Western blot analysis of EseH secreted into the culture supernatant. Anti-HA was used for EseH-HA fusion protein probing, and the antibody against RNAP was used as bacterial cytosolic marker. Data are representative of at least 3 experiments. (C) HeLa cells were infected with wild type $E$. tarda, $\Delta \mathrm{T} 3 \mathrm{SS}$ or $\Delta \mathrm{T} 6 \mathrm{SS}$ carrying constructs expressing fusion proteins of $\beta$-lactamase TEM-1 with EseH at a MOI of 100 for 3 hrs, then incubated for an additional 4 hrs with fresh media. The infected cells were loaded with CCF4/AM, and the translocation of effectors were analyzed by fluorescence microscopy. Blue fluorescence indicates the positive translocation of T3SS- or T6SS-dependent effectors. Data are representative of at least 3 experiments, representative microscopic images are shown.bar=100 uM. * $p<0.05$.

Figure 2. EseH is translocated into the nucleus. (A) Immunofluorescence microscopy analysis of transient expression of EseH-HA or EseG-HA fusion protein in $293 \mathrm{~T}$ cells. Cells were fixed and labeled with anti-HA antibody (green) and nuclei were stained with DAPI (blue). Representative microscopic images are shown. Data are representative of at least 3 experiments. (B) Graph show mean \pm SD of six fields. Data are representative of at least 3 experiments. ${ }^{*} p<0.05$. (C) EseH-HA-transfected 293 T cells lysates were collected, and cell cytosol, membrane and nuclear fractions were separated by gradient centrifugation, and the EseH-HA expression was analyzed by western blot. Cytosol was probed with anti-tubulin antibody. Membrane fraction 
was probed with anti-calnexin antibody. Nuclear fraction was probed by anti-HDAC antibody. Data are representative of at least 3 experiments.

Figure 3. Homology modeling analysis of EseH. (A) Sequence conservation of $E$. piscicida EseH. ClustalW multi-sequence alignment with phosphothreonine lyase family of OspF from Shigella, SpvC from non-typhoid Salmonella serotypes, and HopAI1 from Pseudomonas syringae pv. Tomato DC3000. Aliphatic, hydrophobic amino acids (pink), hydrophobic amino acids (green), aliphatic hydrophilic amino acids (yellow), hydrophilic amino acids (orange) are highlighted, (*) indicates conserved functional sites of phosphothreonine lyase family. (B) Structure modeling of EseH and indicated phosphothreonine lyase family members was performed using the I-TASSER Web server. Images were colored by rainbow $\mathrm{N}$ to $\mathrm{C}$ terminus.

Figure 4. EseH regulates MAPK signaling in $E$. piscicida infected HeLa cells. HeLa cells were infected with E. piscicida strains for 2 hours, and the cell lysates

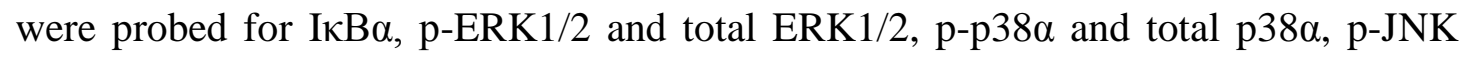
and total JNK. $\beta$-actin is shown as a loading control. EseH-HA was probed to confirm the protein expression. The signal intensities were quantitatively analyzed by NIH ImageJ. Data are representative of at least 3 experiments.

Figure 5. Mutation of predicted lyase catalytic sites of EseH abolishes the MAPK inhibitory activity. Indicated EseH mutants transient expressed 293T cells were pretreated with tumor necrosis factor- $\alpha$. Cell lysates were probed for I $\mathrm{B} \alpha, \mathrm{p}$-ERK1/2 and total ERK1/2, p-p38 $\alpha$ and total p38 $\alpha$, p-JNK and total JNK. EseH-HA was probed to confirm the proteins expression. The signal intensities were quantitatively analyzed by NIH ImageJ. Data are representative of at least 3 experiments. 
Figure 6. Critical role of EseH in promoting virulence and colonization of $E$. piscicida in the zebrafish model. (A) Expression of cytokines of TNF- $\alpha$, IL-10, IL-12, IFN- $\gamma$ in zebrafish tissue infected with wild-type, eseH and complemented eseH E. piscicida. PBS-treated fish were used as a control. The experiments were performed in triplicate with 15 fish in each group. Error bars indicate SD of technical replicates. $* p<0.05$. (B) Survival of zebrafish infected with wild-type, eseH and complemented eseH E. piscicida (50 cfu/fish). N=30 fish per group. Data shown are from at least 3 representative experiments. (C) Bacteria burden in zebrafish liver and kidney was measured at indicated time points after infection with wild-type, eseH and complemented eseH E. piscicida. $\mathrm{N}=5$ fish per group per time point. Data are representative of at least 3 experiments. $* p<0.05$. 


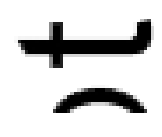

A

\section{DMEM-cultured}

macrophage-released

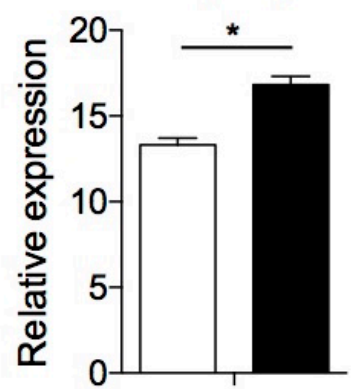

C

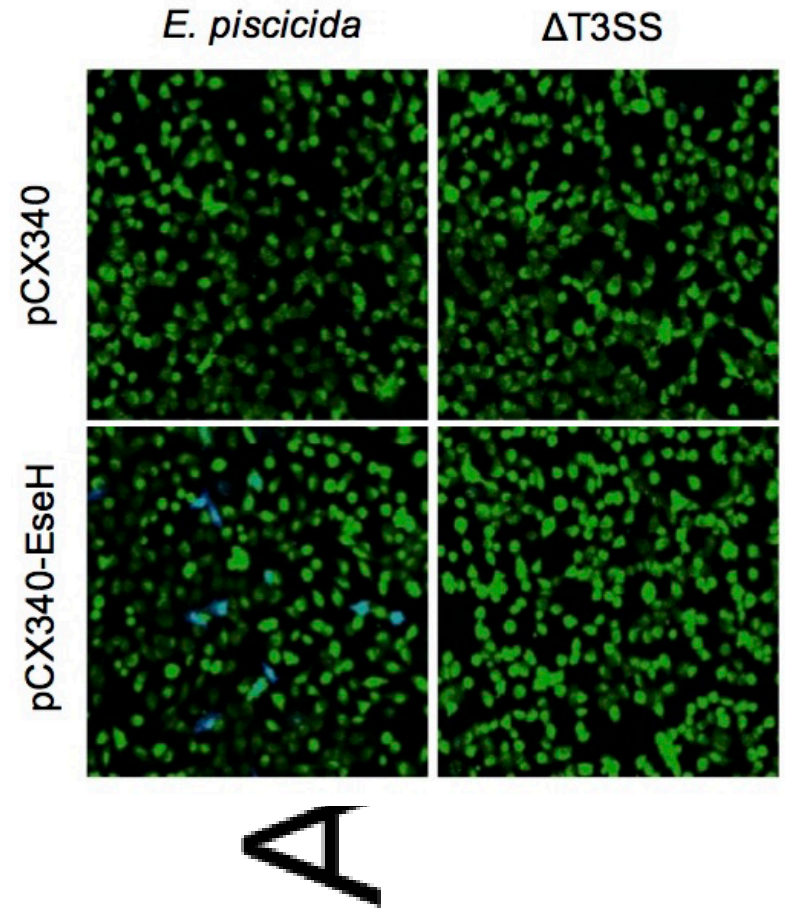

B

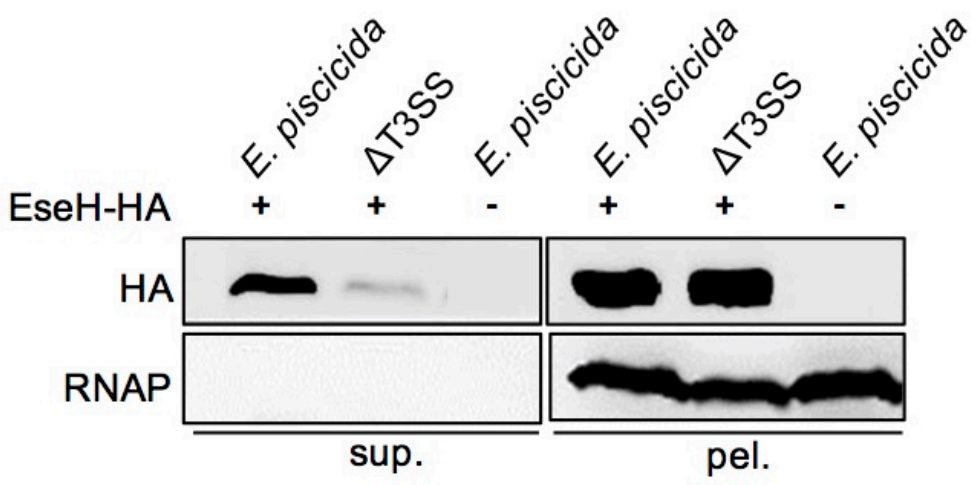

D
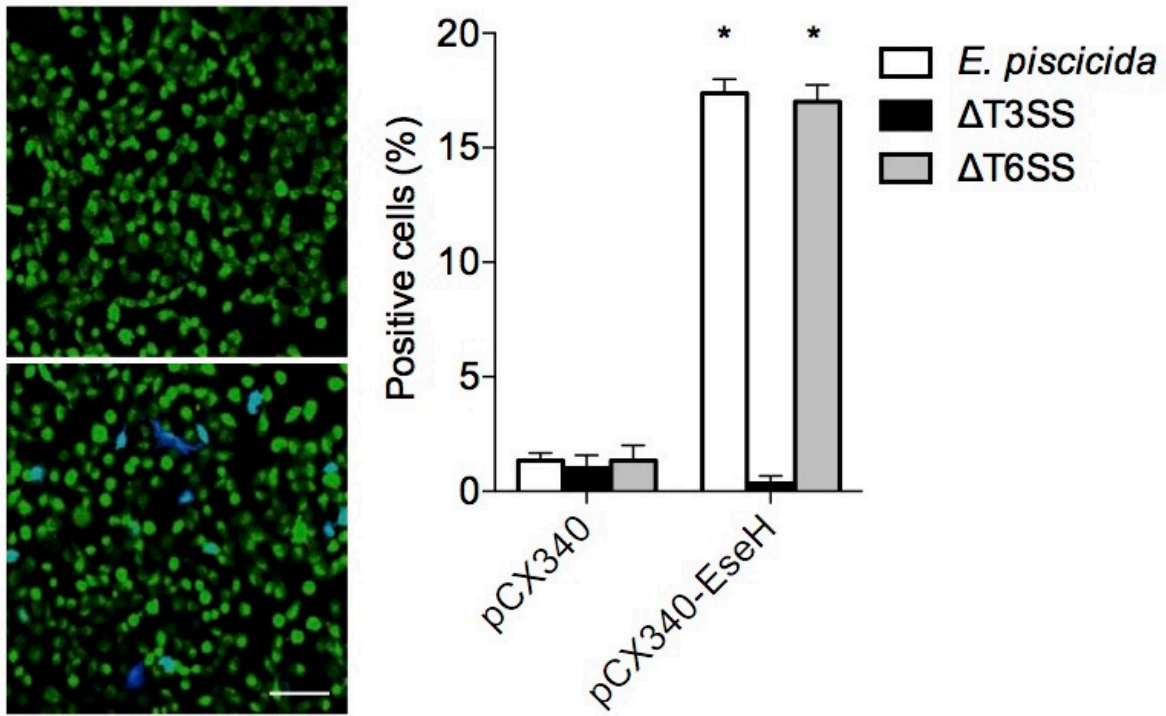

CMI_12638_F1.tiff 


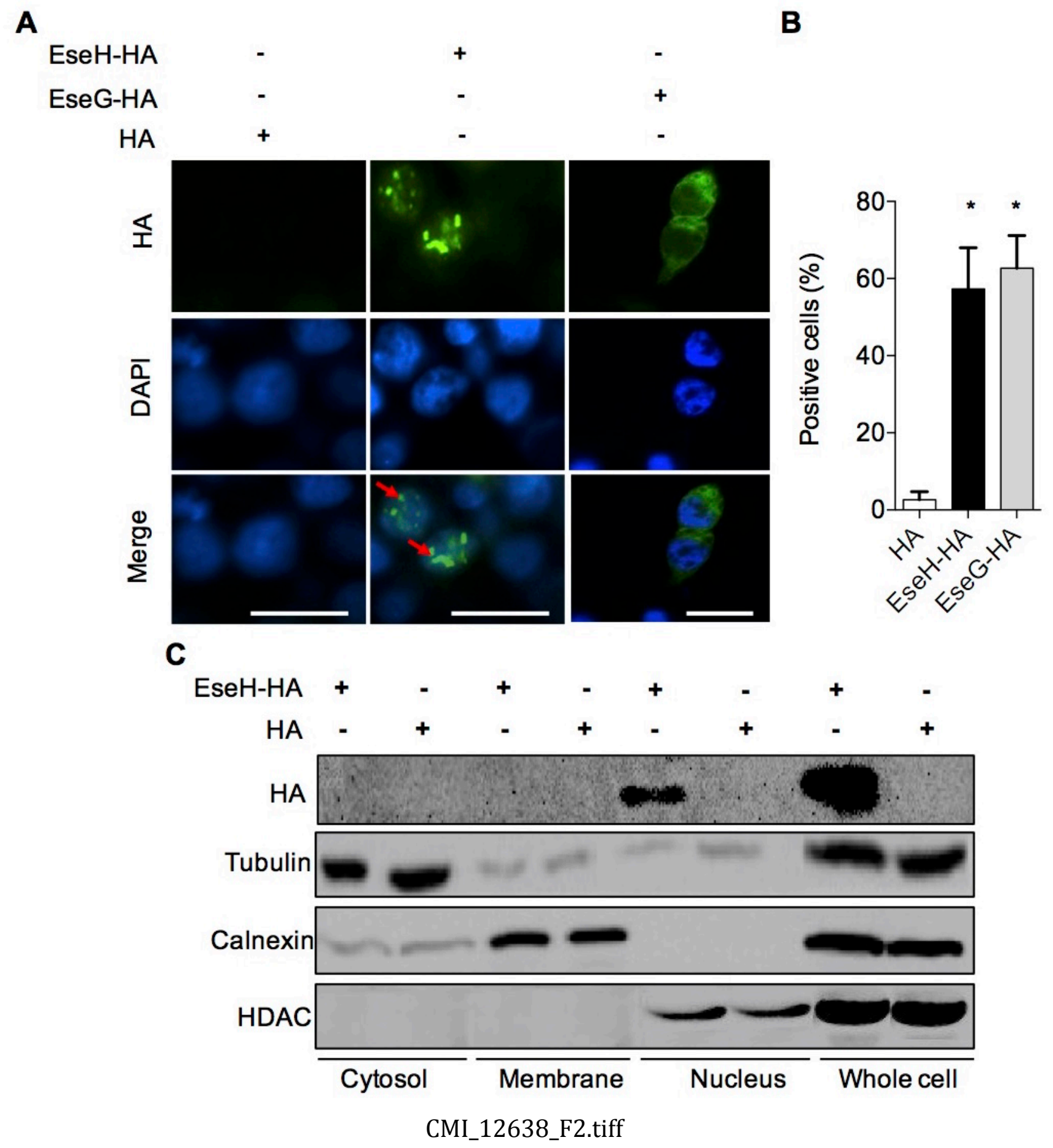

This article is protected by copyright. All rights reserved. 
A

EseH_E. piscicida

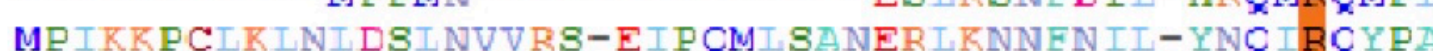
SpvC_Salmonella MPINRPNLNLNI PRINIVAAYDGAEIPSTSKHLKNNENSI-HNQMRKMPV HopA/1_DC3000 MIALRINTSIAQARIK------------KNAEAEIRHMNHAEVRAHTP

EseH E. piscicida

60

70

80

90

OspF_Shigella SpvC_Sälmonella HopAI1_DC3000
SHFTVEPNZEDYSGIR YYFRVASNVETYSDIC SHFREAIDVEDYSGMR TRETLNHRA EMY-EV
SGE $A$ A SQGERI SN----ASDDHE IFARREAI E-ESVMYGGEGIVN----HSGDVEIF ACRENR SGFEAMSQGEQINN----HGYDVE IHARRESP SAIGENHGGWTA VNK ERVTESEVE IFMER SDS
110

120

130

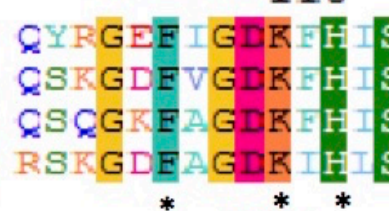
160

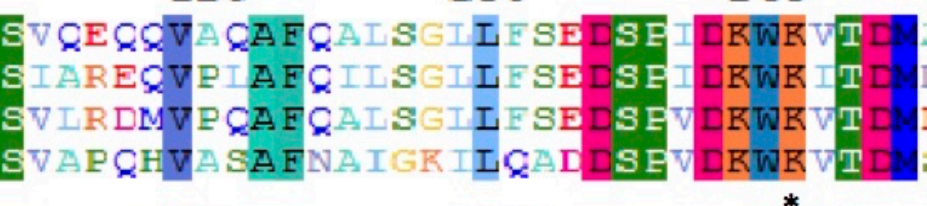

170

180

$1 \stackrel{*}{90}$

200

EseH_E. piscicida OspF Shigella SpvC_Salmonella HopAI/1_DC3000

$---\mathrm{QgSRV}$ EGA

- QQSRVGIGA

$---\mathrm{QRLRVSIGD}$

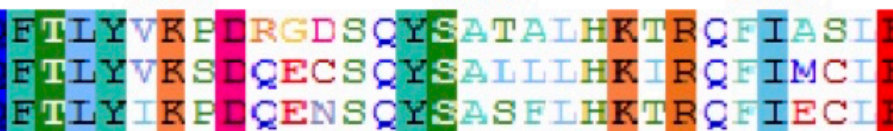
SRISE SNIIR CPERIRUTCG **

EseH_E. piscicida GGIIRG-RVEESDVHEDSWRYISYRMEIRSER G EMPSCIIREERFYRI OspF_Shigella SKIAPG-EYEASDVREEDWYVSYRNE RSDRDGSER EQMLREERYRI SpvC_Sälmonella MGVISG-QGEESDVHEENWKYISYRNEIRSGRDGGEM RQIREERFYRI

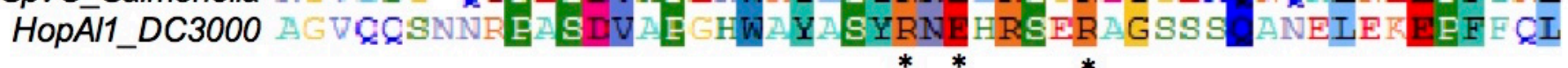

$\begin{array}{rcc} & 260 & 270 \\ \text { EseH_E. piscicida } & \mathrm{MTE}-------------------- \\ \text { OspF_Shigella } & \mathrm{MIE}-------------------- \\ \text { SpvC_Salmonella } & \mathrm{MTE}-----------------------\end{array}$

HopĀ1_DC3000 VSEPDVAASPVKSGASSRSIMPPPWTF

B
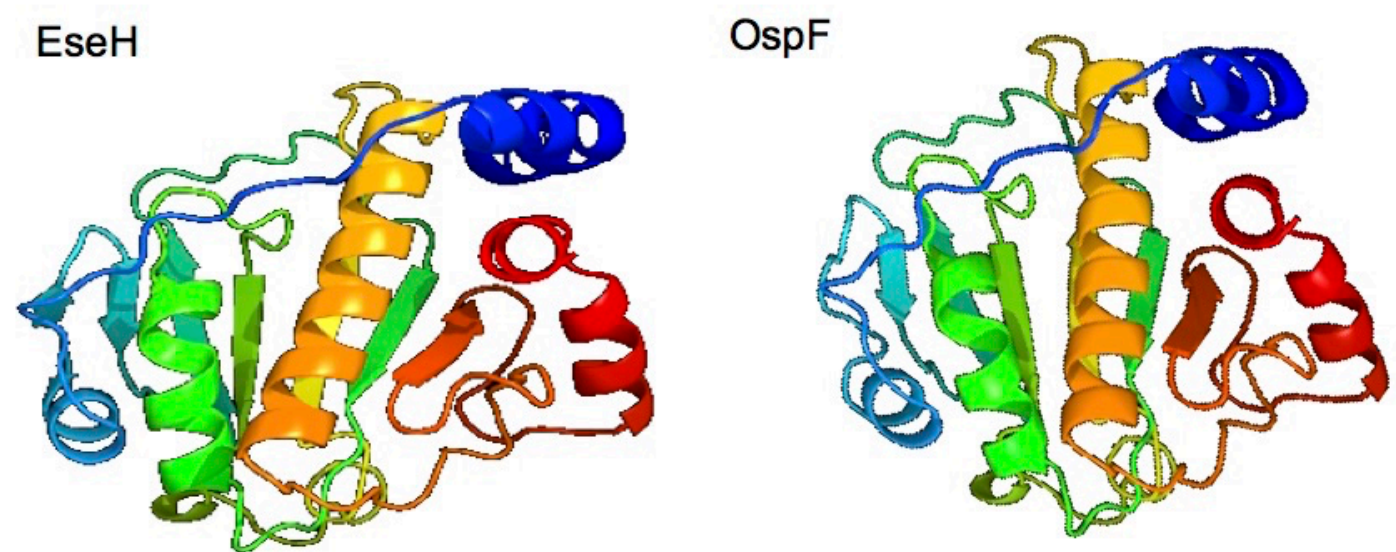

SpvC

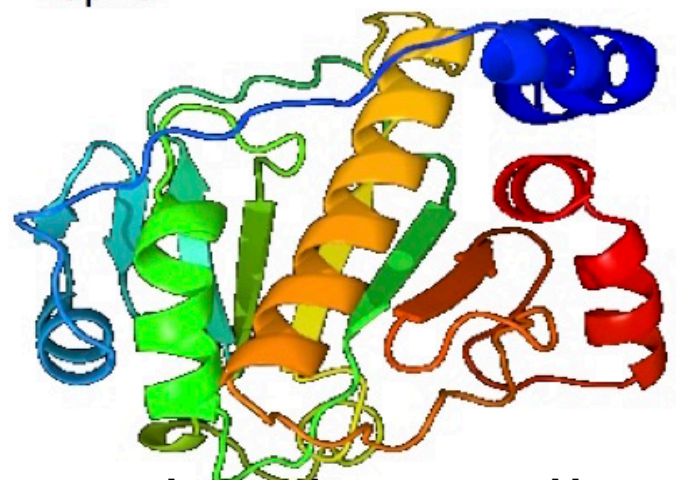

HopAl1

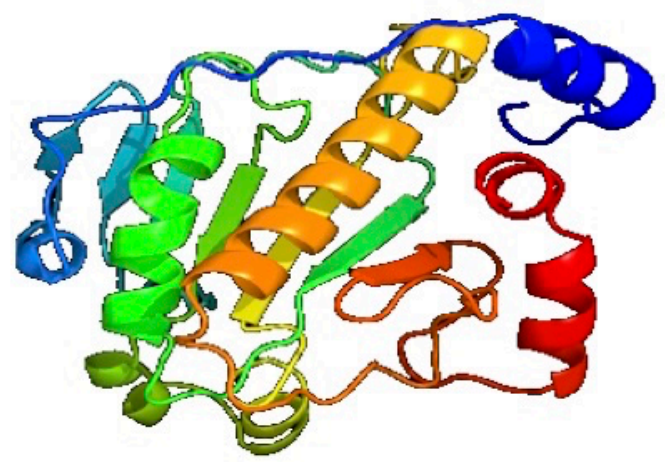

This article is protected by copyright. All rights reserved. 


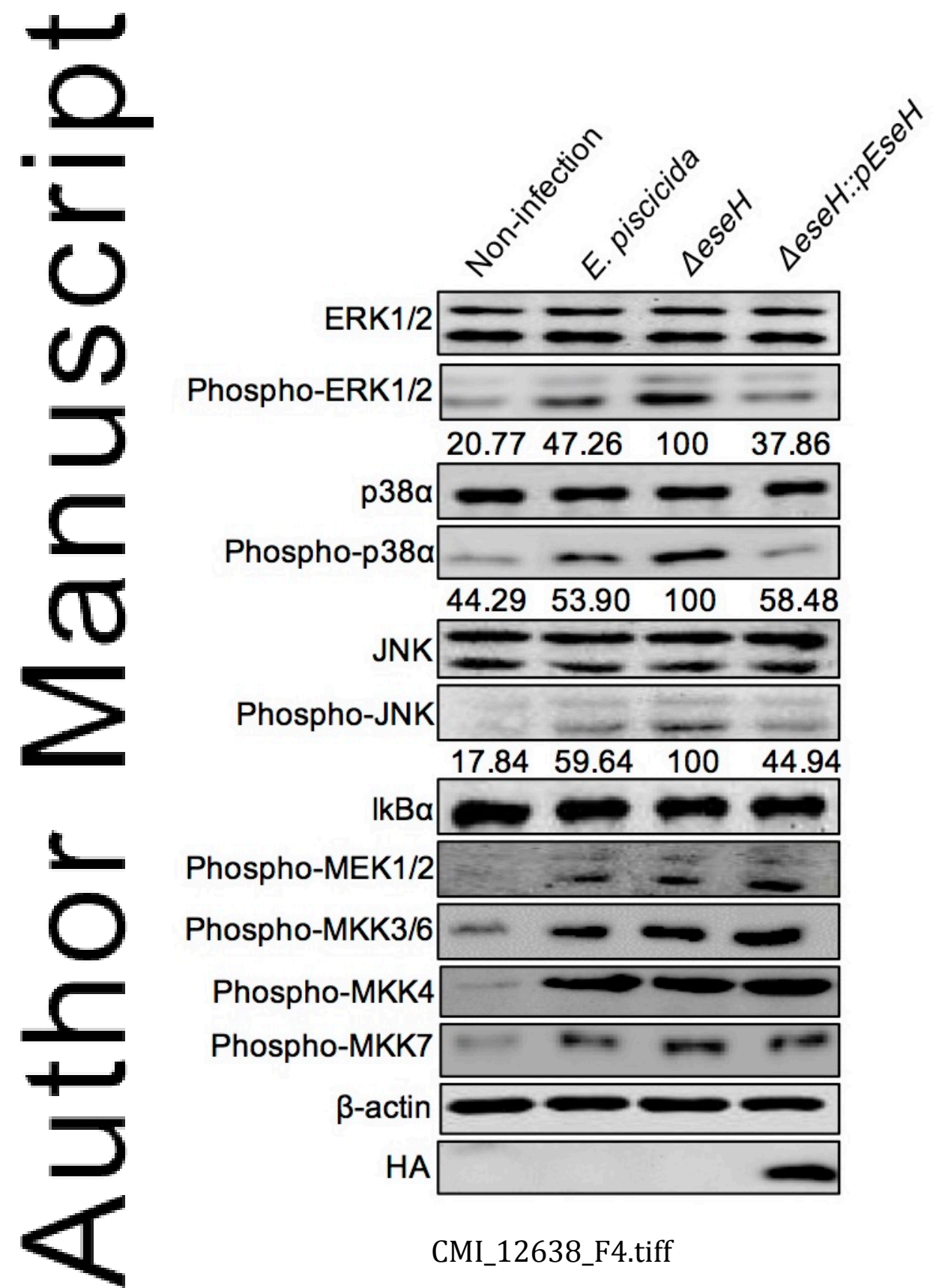

This article is protected by copyright. All rights reserved. 


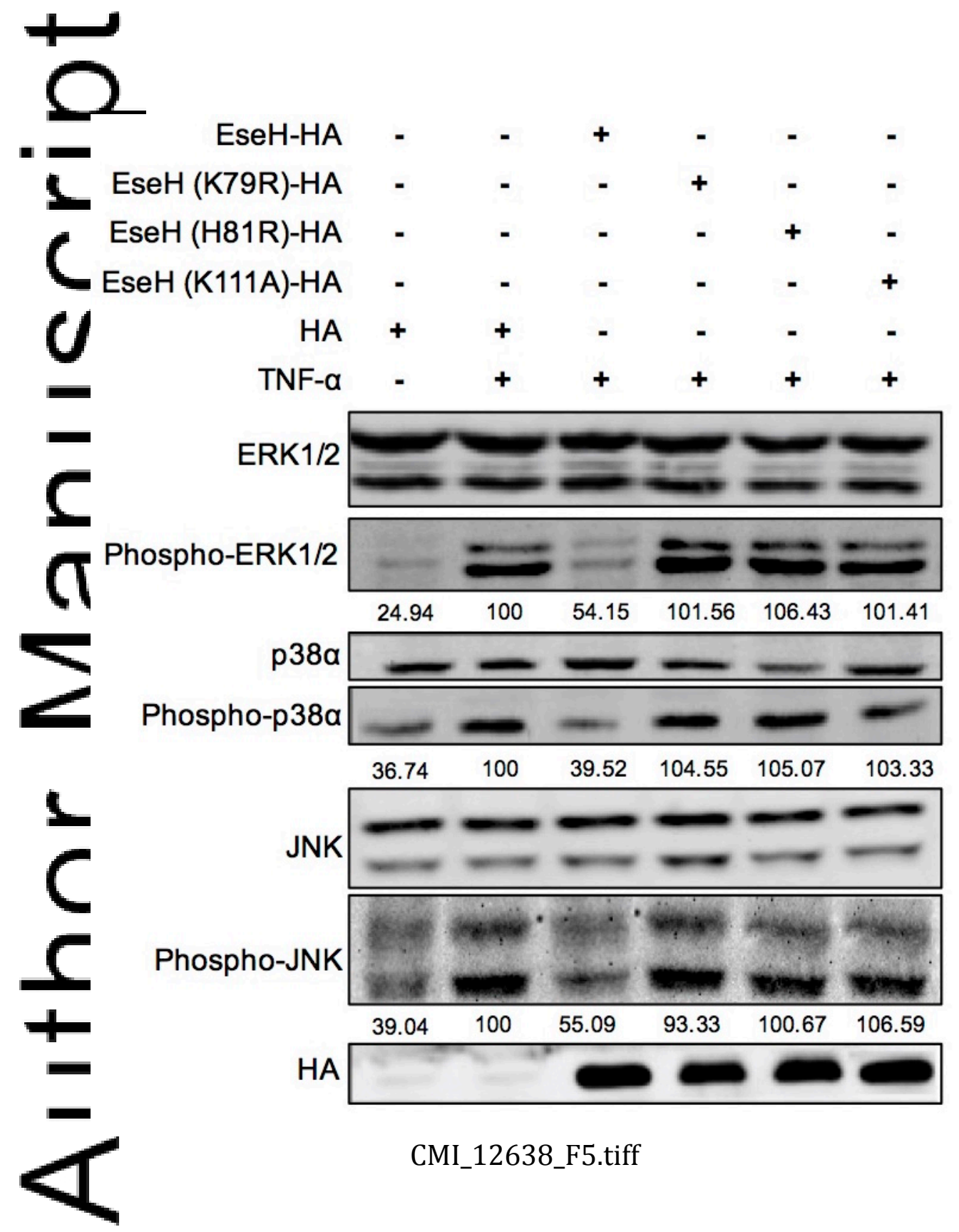

This article is protected by copyright. All rights reserved. 


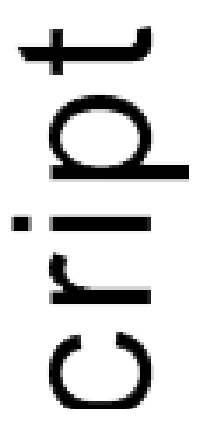

A

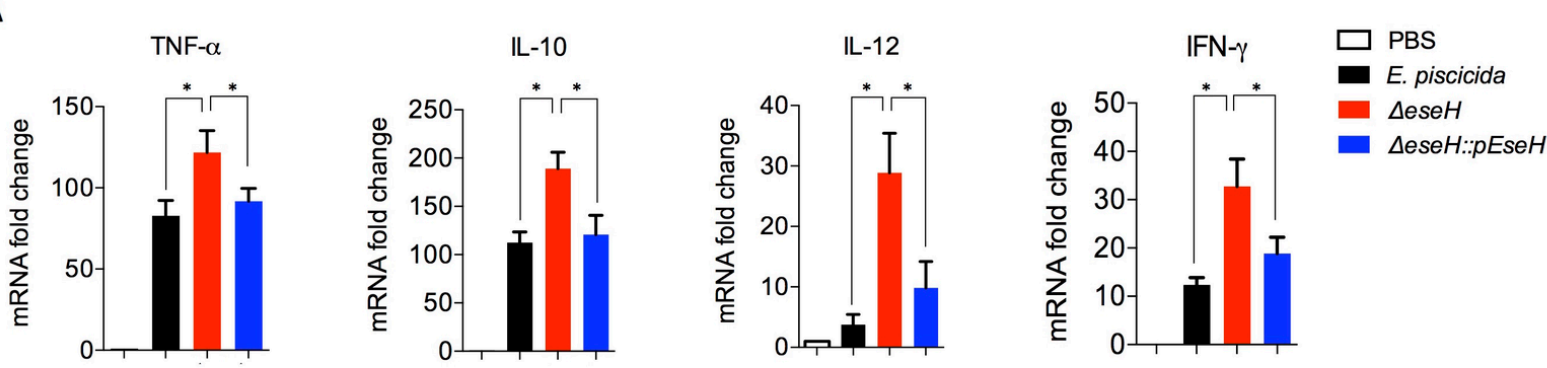

B
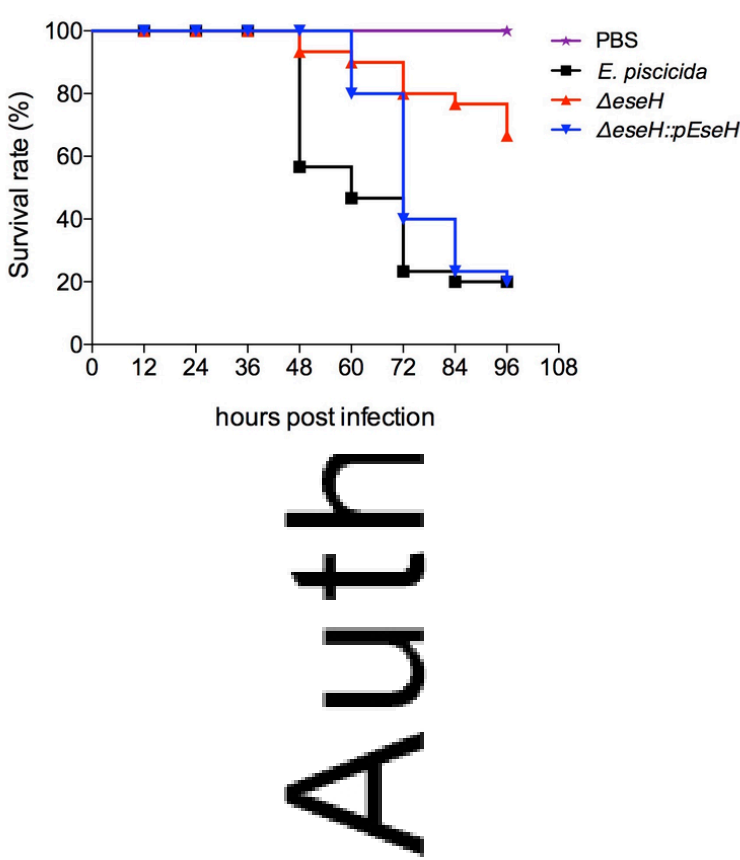

C

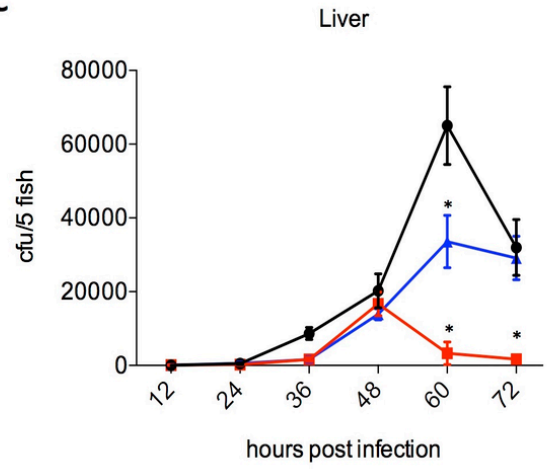

CMI_12638_F6.tiff

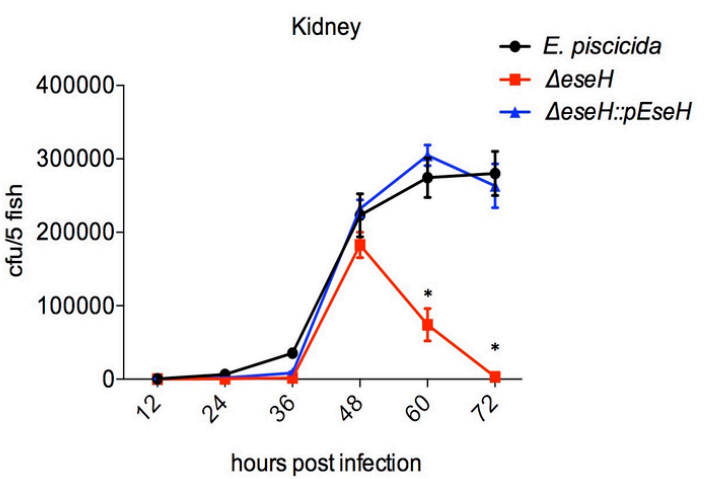

hours post infection 